\title{
High positive end-expiratory pressure: only a dam against oedema formation?
}

\author{
Alessandro Protti ${ }^{*}$, Davide T Andreis ${ }^{2}$, Giacomo E lapichino ${ }^{2}$, Massimo Monti ${ }^{2}$, Beatrice Comini ${ }^{2}$, Marta Milesi ${ }^{2}$, \\ Loredana Zani ${ }^{2}$, Stefano Gatti ${ }^{3}$, Luciano Lombardi ${ }^{4}$ and Luciano Gattinoni ${ }^{1,2}$
}

\begin{abstract}
Introduction: Healthy piglets ventilated with no positive end-expiratory pressure (PEEP) and with tidal volume $\left(V_{T}\right)$ close to inspiratory capacity (IC) develop fatal pulmonary oedema within $36 \mathrm{~h}$. In contrast, those ventilated with high PEEP and low $V_{T}$, resulting in the same volume of gas inflated (close to IC), do not. If the real threat to the blood-gas barrier is lung overinflation, then a similar damage will occur with the two settings. If PEEP only hydrostatically counteracts fluid filtration, then its removal will lead to oedema formation, thus revealing the deleterious effects of overinflation.

Methods: Following baseline lung computed tomography $(C T)$, five healthy piglets were ventilated with high PEEP (volume of gas around $75 \%$ of IC) and low $V_{T}$ (25\% of IC) for $36 \mathrm{~h}$. PEEP was then suddenly zeroed and low $\mathrm{V}_{T}$ was maintained for $18 \mathrm{~h}$. Oedema was diagnosed if final lung weight (measured on a balance following autopsy) exceeded the initial one $(C T)$.

Results: Animals were ventilated with PEEP $18 \pm 1 \mathrm{cmH}_{2} \mathrm{O}$ (volume of gas $875 \pm 178 \mathrm{ml}, 89 \pm 7 \%$ of IC) and $\mathrm{V}_{T} 213 \pm$ $10 \mathrm{ml}\left(22 \pm 5 \%\right.$ of IC) for the first $36 \mathrm{~h}$, and with no PEEP and $\mathrm{V}_{\mathrm{T}} 213 \pm 10 \mathrm{ml}$ for the last $18 \mathrm{~h}$. On average, final lung weight was not higher, and actually it was even lower, than the initial one (284 $\pm 62 \mathrm{vs} .347 \pm 36 \mathrm{~g} ; P=0.01)$.

Conclusions: High PEEP (and low $V_{T}$ ) do not merely impede fluid extravasation but rather preserve the integrity of the blood-gas barrier in healthy lungs.
\end{abstract}

\section{Introduction}

Mechanical ventilation is a pivotal therapy for respiratory failure, although overinflation may injure the lung [1-3].

We have recently shown that healthy piglets ventilated with no positive end-expiratory pressure (PEEP) and with tidal volume $\left(\mathrm{V}_{\mathrm{T}}\right)$ close to inspiratory capacity (IC) die with inflammatory pulmonary oedema within $36 \mathrm{~h}$. In contrast, those ventilated with high PEEP $\left(\geq 18 \mathrm{cmH}_{2} \mathrm{O}\right.$; volume of gas around $75 \%$ of IC) and low $\mathrm{V}_{\mathrm{T}}$ (25\% of IC) survive with normal lungs for $54 \mathrm{~h}$ [4].

Inflammatory pulmonary oedema develops when lung capillary transmural (internal minus external) pressure drives excessive fluid filtration through a disrupted, highly permeable, blood-gas barrier [5]. As a result, exudates accumulate in the extravascular space and lung

\footnotetext{
* Correspondence: alessandro.protti@policlinico.mi.it

'Dipartimento di Anestesia, Rianimazione (Intensiva e Subintensiva) e Terapia del Dolore, Fondazione IRCCS Ca' Granda - Ospedale Maggiore Policlinico,

via Francesco Sforza, 35, 20122 Milan, Italy

Full list of author information is available at the end of the article
}

weight increases [6,7]. If overinflation per se is the real threat to the blood-gas barrier [8], then ventilation with large $\mathrm{V}_{\mathrm{T}}$ alone (100\% of IC) will be as harmful as ventilation with high PEEP (75\% of IC) and low $\mathrm{V}_{\mathrm{T}}$ (25\% of IC). In fact, in both cases, the volume of gas globally inflated will be equal to IC. However, high PEEP (and low $V_{T}$ ) will possibly impede extravasation by lowering venous return, cardiac output and pulmonary capillary inflow (and pressure) while increasing extravascular pressure $[9,10]$. Oedema will then not develop even if the blood-gas barrier loses its integrity.

To test this hypothesis, we ventilated healthy piglets with high PEEP (and low $\mathrm{V}_{\mathrm{T}}$ ) (as above) and then suddenly removed PEEP to allow free extravasation through a possibly disrupted blood-gas barrier. Lung weight was expected to increase as oedema formation was no longer impeded.

\section{Biomed Central}

(c) 2013 Protti et al.; licensee BioMed Central Ltd. This is an open access article distributed under the terms of the Creative Commons Attribution License (http://creativecommons.org/licenses/by/2.0), which permits unrestricted use, distribution, and reproduction in any medium, provided the original work is properly cited. 


\section{Materials and methods}

The study complied with international recommendations [11] and was approved by the Italian Ministry of Health (protocol number 01/10).

Five healthy, sedated and paralysed piglets $(21 \pm 1 \mathrm{~kg})$ were surgically prepared in supine position. They were then turned prone and ventilated with no PEEP and with a $V_{\mathrm{T}}$ of $10 \mathrm{ml} / \mathrm{kg}$ of body weight (Engström Carestation, GE Healthcare; Madison, WI, USA). Lung computed tomography $\left(\mathrm{CT}\right.$ ) was taken at $0 \mathrm{cmH}_{2} \mathrm{O}$ (functional residual capacity, FRC), around $18 \mathrm{cmH}_{2} \mathrm{O}$ (the level of PEEP planned to be used) (see below) and $45 \mathrm{cmH}_{2} \mathrm{O}$ (arbitrarily defined as total lung capacity, TLC) of airway pressure. Lung gas volumes and weight were measured by quantitative analysis [12].

Following this pre-study period, PEEP was set around $18 \mathrm{cmH}_{2} \mathrm{O}$ while $\mathrm{V}_{\mathrm{T}}$ was kept constant (PEEP phase). Based on a previous study [4], we expected that the volume of gas so inflated in the form of PEEP would have been around $75 \%$ and $\mathrm{V}_{\mathrm{T}}$ around $25 \%$ of IC (TLC minus FRC). Therefore, the volume of gas inflated by end of inspiration (volume of gas due to PEEP plus $\mathrm{V}_{\mathrm{T}}$ ) was predicted to be equal to IC and end-inspiratory lung volume, including FRC, to approach TLC. This setting was kept constant for $36 \mathrm{~h}$ (PEEP phase). PEEP was then suddenly zeroed and $\mathrm{V}_{\mathrm{T}}$ was maintained for $18 \mathrm{~h}$ (ZEEP phase) (Figure 1).

Results of the lung CT scan analysis became available once the study had already started. They did not influence the setting described above but permitted exact computation of volumes of gas effectively inflated (as PEEP and $\mathrm{V}_{\mathrm{T}}$ ) in relation to lung capacities.

During the entire 54-h study period the animals were kept prone, in $10^{\circ}$ Trendelemburg position [13]. Respiratory rate was 15 breaths per minute, inspiratory-to-expiratory time ratio 1:2 (1:3 if intrinsic PEEP developed) and inspired oxygen fraction was 0.50 . Tracheal suctioning and recruitment manoeuvres were only performed before applying PEEP and after its removal. Use of normal saline and norepinephrine was standardised to try to maintain mean arterial pressure above $60 \mathrm{mmHg}$. Respiratory system and lung mechanics, blood gas analysis and haemodynamics (including cardiac output by thermodilution) were assessed every $6 \mathrm{~h}$. Data were also collected during the pre-study period (baseline) and soon after PEEP removal (time 0 of the ZEEP phase). Transpulmonary pressure was computed as (end-inspiratory airway pressure) - [(end-inspiratory oesophageal pressure) - (oesophageal pressure at $0 \mathrm{cmH}_{2} \mathrm{O}$ of airway pressure)]). Transmural pulmonary arterial and pulmonary artery occlusion pressures were computed as (endexpiratory intravascular pressures) - [(end-expiratory oesophageal pressure) - (oesophageal pressure at $0 \mathrm{cmH}_{2} \mathrm{O}$ of airway pressure)]) [14]. Urinary output was recorded every hour and water balance was computed as the difference between saline infusion and urinary output.

At the end of the study, animals were sacrificed (potassium chloride, $40 \mathrm{mEq}$ intravenous) and exsanguinated. Lungs were excised and weighted on a balance. This (final) lung weight was compared with the initial one, measured on pre-study CT taken at $0 \mathrm{cmH}_{2} \mathrm{O}$ of airway pressure (the degree of agreement between these two methods for measuring lung weight was assessed in five other piglets, as reported in Additional file 1). Pulmonary oedema was diagnosed if lung weight had increased across the entire study period. The right lung was used for the calculation of wet-to-dry weight ratio and blind histological examination [15]. Twelve piglets uneventfully ventilated for $54 \mathrm{~h}$ with no PEEP and low $\mathrm{V}_{\mathrm{T}}$ (as part of a previous study [3]) that did not develop pulmonary oedema were used as controls.

\section{Statistical analysis}

Numerical data are reported as mean \pm standard deviation. Based on distribution (Shapiro-Wilk test), they were analysed using Student's (paired) $t$ test or Mann-Whitney rank sum test, one-way repeated measures analysis of variance (RM ANOVA) or RM ANOVA on ranks. Post hoc comparisons were done using the Holm-Sidak or Dunn's method. Categorical data are reported as median (interquartile range) and were analysed using the MannWhitney rank sum test. A $P$ value $<0.05$ was considered significant (SigmaPlot 11.0, Jandel Scientific Software; San Jose, CA, USA).

For more information on methods, please refer to Additional file 2 .

\section{Results}

Animals were ventilated with PEEP $18 \pm 1 \mathrm{cmH}_{2} \mathrm{O}$ and $\mathrm{V}_{\mathrm{T}} 213 \pm 10 \mathrm{ml}$ for the first $36 \mathrm{~h}$ (PEEP phase) and with no PEEP and $V_{T} 213 \pm 10 \mathrm{ml}$ for the last $18 \mathrm{~h}$ (ZEEP phase).

On baseline lung CT (Additional file 3), application of PEEP $18 \pm 1 \mathrm{cmH}_{2} \mathrm{O}$ resulted in inflation of $875 \pm 178 \mathrm{ml}$ of gas, equal to $89 \pm 7 \%$ of estimated IC $(988 \pm 176 \mathrm{ml})$. $\mathrm{V}_{\mathrm{T}}$ was $22 \pm 5 \%$ of estimated IC. The volume of gas inflated by end of inspiration during the PEEP phase (volume of gas due to PEEP plus $\mathrm{V}_{\mathrm{T}}$ ) was slightly higher than estimated IC $(1088 \pm 177$ vs. $988 \pm 176 \mathrm{ml}, P=0.05)$. End-inspiratory lung volume, including FRC (425 \pm 66 $\mathrm{ml})$, was slightly higher than estimated TLC (1512 \pm 229 vs. $1413 \pm 225 \mathrm{ml}, P=0.05$ ).

Changes in systemic and pulmonary haemodynamics are shown in Figure 2. Mean arterial pressure (and cardiac output) diminished soon after the application of PEEP despite aggressive fluid resuscitation and norepinephrine infusion (Additional file 4), but returned to baseline before 


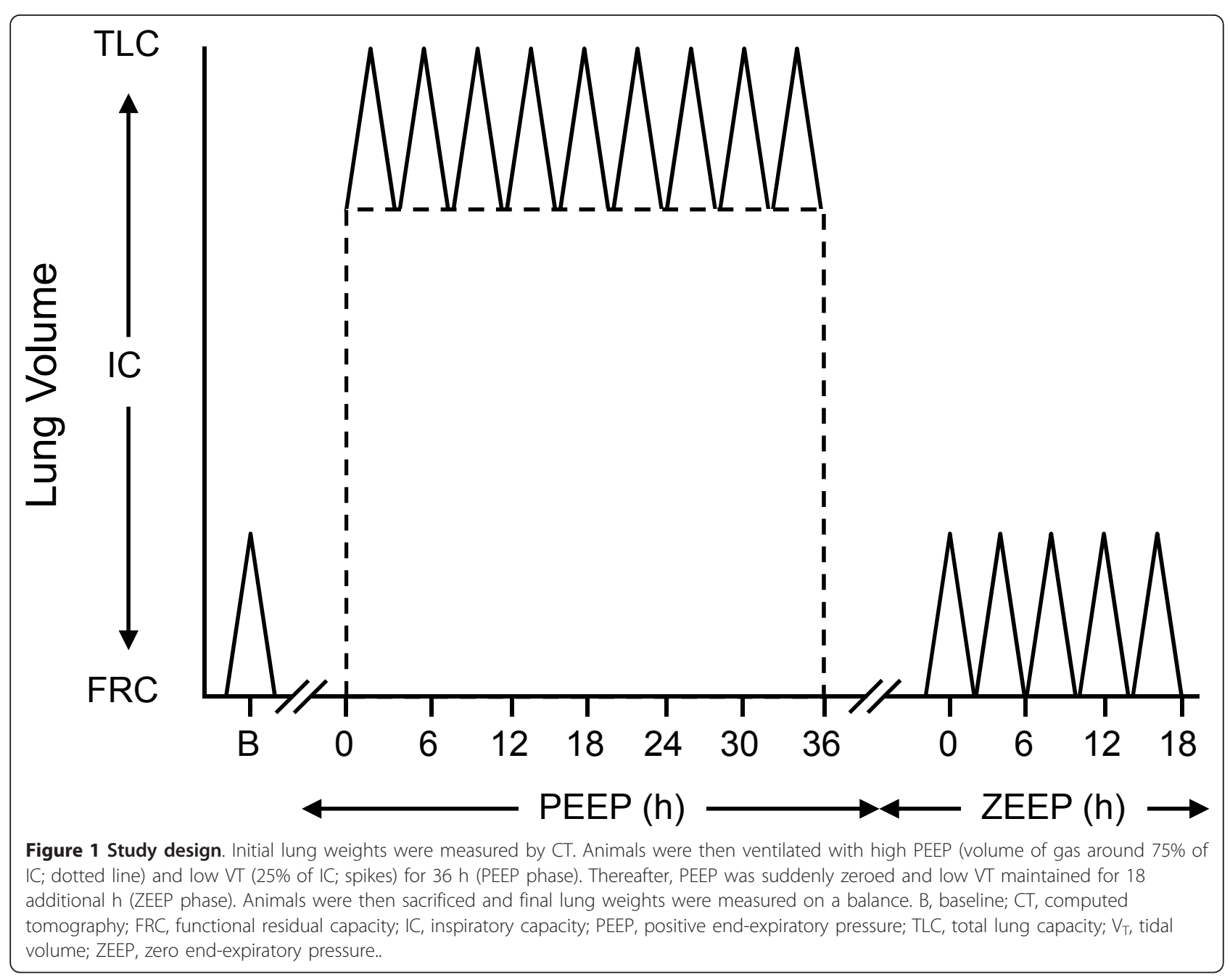

PEEP was removed. Transmural mean pulmonary arterial pressure did not change over time while transmural pulmonary artery occlusion pressure tended to be higher than pre-study values following PEEP removal. By the end of the experiment, water balance ranged between +1600 and $+6400 \mathrm{ml}$ and body weight had accordingly increased (from $21 \pm 1$ to $25 \pm 2 \mathrm{~kg}, P=0.01$ ).

Respiratory system mechanics, lung mechanics and gas exchange did not deteriorate during the PEEP phase (Additional file 5). Nonetheless, data recorded immediately after PEEP removal were slightly worse than those collected at baseline; as far as subsequent oedema formation was concerned, no further change occurred during the ZEEP phase (Table 1).

At autopsy, lungs looked pink and normally inflated, except for small areas of atelectasis (Additional file 6). Final lung weights did not exceed initial ones (Figure 3 ). Lung wet-to-dry weight ratio $(5.1 \pm 0.3$ vs. $4.8 \pm 0.7, P$ $=0.38$ ) and histology (Table 2 ) did not differ from those of controls.

\section{Discussion}

Healthy piglets ventilated with high PEEP and low $\mathrm{V}_{\mathrm{T}}$ for $36 \mathrm{~h}$ do not develop pulmonary oedema when airway pressure is suddenly lowered (by removing PEEP). This proves that high PEEP and low $\mathrm{V}_{\mathrm{T}}$ do not permanently alter the integrity of the alveolar-capillary interface even if lung inflation approaches its upper physiological limit (volume of gas globally inflated equal to IC).

We have previously shown that healthy piglets ventilated for $54 \mathrm{~h}$ with high PEEP (never removed) and low $\mathrm{V}_{\mathrm{T}}$ survive with normal lungs [4]. There, lack of pulmonary oedema could have been attributed to diminished transmural pulmonary capillary pressure (that drives fluid extravasation) across an abnormally highly permeable (overstretched) blood-gas barrier. In fact, application of high PEEP always caused hypotension and low cardiac output while lungs were maximally inflated [4].

PEEP may or may not prevent lung oedema (or even worsen it) depending on relative changes in pulmonary intravascular and extravascular (alveolar and extra-alveolar) 


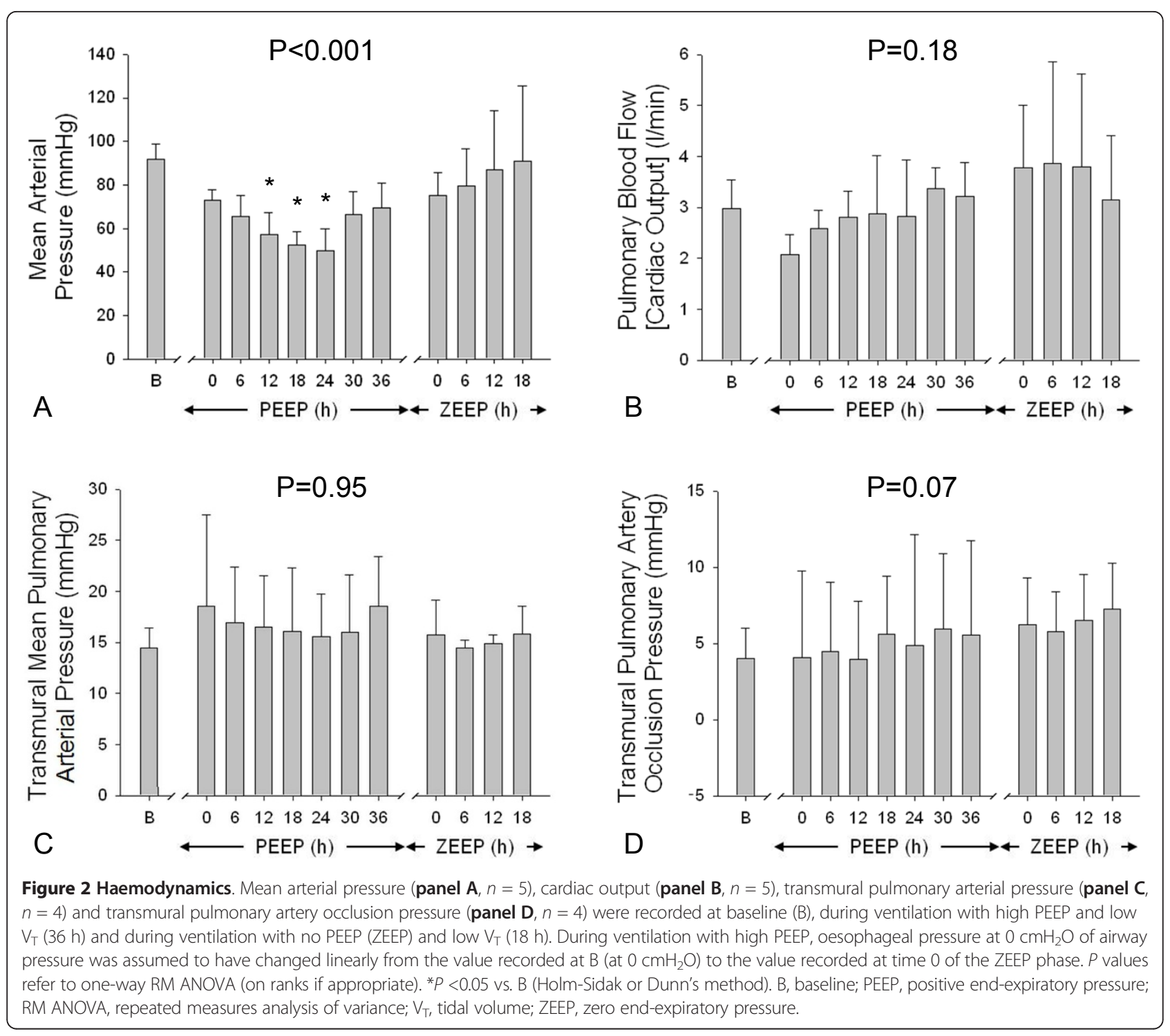

Table 1 Lung function

\begin{tabular}{|c|c|c|c|c|c|c|}
\hline & \multirow[t]{2}{*}{ Baseline } & \multicolumn{4}{|c|}{ Ventilation with no PEEP (ZEEP phase) } & \multirow[t]{2}{*}{$P$} \\
\hline & & $\mathrm{Oh}$ & $6 \mathrm{~h}$ & $12 \mathrm{~h}$ & $18 \mathrm{~h}$ & \\
\hline End-inspiratory airway pressure $\left(\mathrm{cmH}_{2} \mathrm{O}\right)$ & $10 \pm 1$ & $14 \pm 3^{*}$ & $13 \pm 2^{*}$ & $13 \pm 3^{*}$ & $13 \pm 3^{*}$ & 0.002 \\
\hline Transpulmonary pressure $\left(\mathrm{cmH}_{2} \mathrm{O}\right)$ & $5 \pm 2$ & $10 \pm 3^{*}$ & $9 \pm 3^{*}$ & $9 \pm 3^{*}$ & $10 \pm 4^{*}$ & 0.001 \\
\hline $\begin{array}{l}\text { Arterial oxygen } \\
\text { tension }(\mathrm{mmHg})\end{array}$ & $222 \pm 43$ & $187 \pm 58$ & $181 \pm 44$ & $180 \pm 47$ & $186 \pm 24$ & 0.11 \\
\hline Arterial carbon dioxide tension $(\mathrm{mmHg})$ & $41 \pm 3$ & $36 \pm 4$ & $39 \pm 4$ & $38 \pm 3$ & $39 \pm 3$ & 0.16 \\
\hline
\end{tabular}

Respiratory system mechanics, lung mechanics and gas exchange at baseline and during ventilation with no PEEP (ZEEP phase) (18 h). End-inspiratory airway pressure was recorded during a 5 -sec end-inspiratory pause. $P$ values refer to one-way RM ANOVA (on ranks if appropriate). ${ }^{*} P<0.05$ vs. baseline (Holm-Sidak or Dunn's method). PEEP, positive end-expiratory pressure; ZEEP, zero end-expiratory pressure; RM ANOVA, repeated measures analysis of variance.

pressures, lung surface area (through which filtration occurs), pulmonary endothelium and epithelium porosity [16-20]. Since its initial use, PEEP was mainly thought to tamponade great veins (thus lowering pulmonary blood flow and pressure) and 'exert an opposing force tending to hinder the outpouring of both red corpuscles and serum from the pulmonary capillaries' [21]. Other means of lowering intravascular pulmonary pressure, such as phlebotomy or vasodilatation, can attenuate pulmonary oedema formation, even if the blood-gas barrier is abnormally 


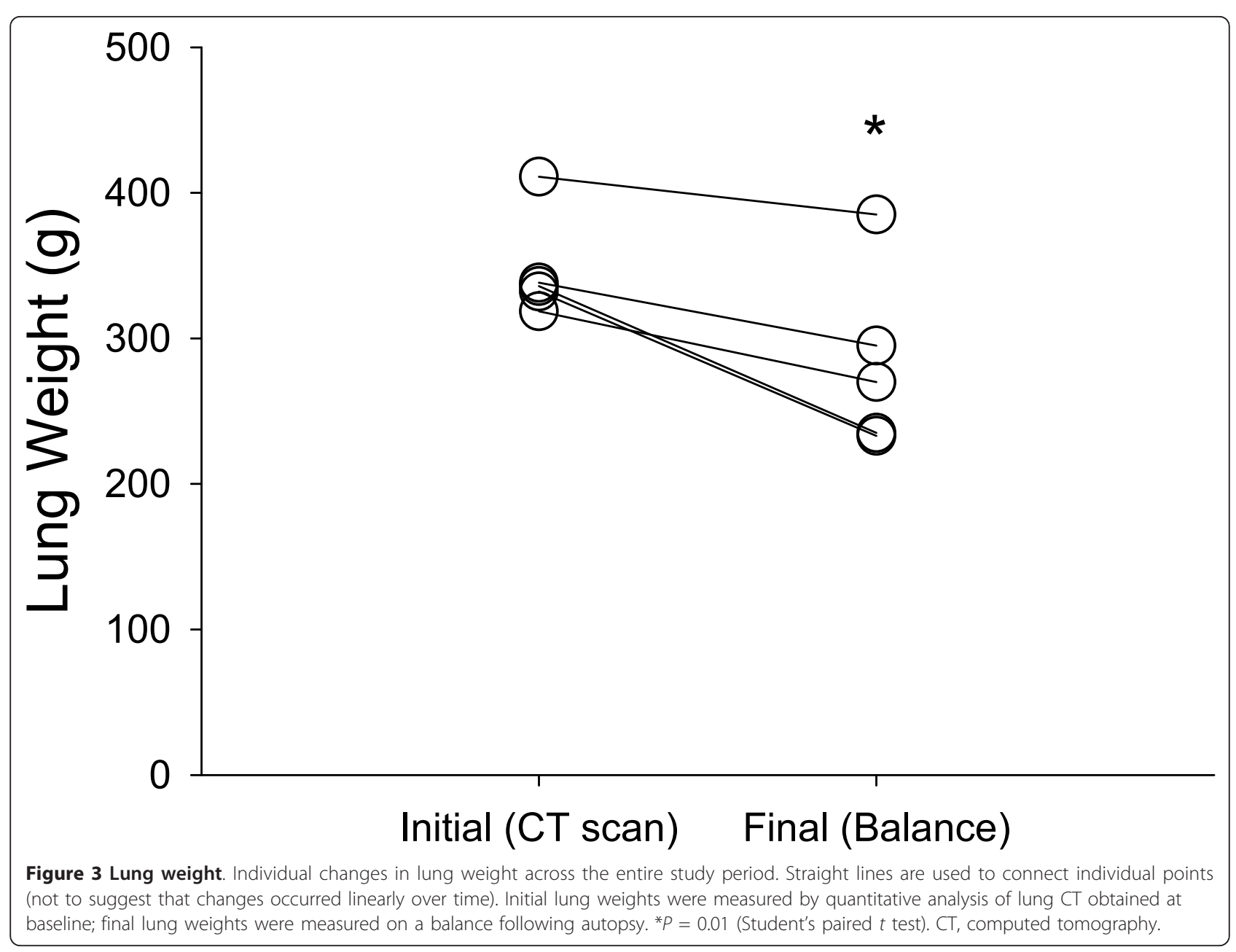

permeable [22,23]. On the other side, increasing transmural pulmonary capillary pressure with dopamine [8] or fluids [24-26] aggravates inflammatory pulmonary oedema and 'sudden removal of a previously existing backward pressure on the pulmonary capillaries (that is PEEP) is followed by an increased permeability of the capillary wall' and leakage of serum [21]. Therefore, lack of oedema per se does not prove that high PEEP and low $\mathrm{V}_{\mathrm{T}}$ are safe.

In this present work, we specifically addressed one of the mechanisms possibly underlying our [4] and others' $[6,8]$ previous findings (namely, diminished pulmonary capillary filtration pressure) by abruptly removing a potential obstacle to oedema formation (high PEEP itself). We ventilated healthy piglets with high PEEP and low $V_{T}$ (volume of gas globally inflated around estimated IC) for $36 \mathrm{~h}$. By this time, animals ventilated with large $\mathrm{V}_{\mathrm{T}}$ alone (always resulting in the same end-inspiratory lung volume) develop overt pulmonary oedema, as indicated by heavy and congested lungs, altered respiratory system mechanics and gas exchange, and pulmonary and systemic inflammation [3]. Since lung injury may not become macroscopically evident as long as PEEP counteracts fluid filtration, PEEP was then suddenly zeroed. Fluid filtration should have freely occurred, driven by normal (and occasionally supra-normal) haemodynamics, had the blood-gas barrier been disrupted [18,24,27].

Acting similarly, we have previously demonstrated a small, non-significant increase in lung weight following PEEP removal in four healthy piglets, finally ventilated with low $\mathrm{V}_{\mathrm{T}}$ for $3 \mathrm{~h}$ [4]. In order to exclude that overt pulmonary oedema could have developed had the experiments lasted longer, we decided to extend the duration of ventilation with low $\mathrm{V}_{\mathrm{T}}$ and no PEEP to $18 \mathrm{~h}$. Even so, lung weight did not increase (and it actually decreased, possibly as a consequence of exsanguination [28]) and mechanics and gas exchange did not deteriorate with time. This proves that ventilation with high PEEP and low $\mathrm{V}_{\mathrm{T}}$ over the previous $36 \mathrm{~h}$ had not grossly and permanently altered the permeability of the blood-gas barrier. The minor decrease in pulmonary compliance and arterial oxygenation that became evident when PEEP was removed (and did not worsen over time) was possibly related to 
Table 2 Lung histology

\begin{tabular}{|c|c|c|c|}
\hline & $\begin{array}{l}\text { Present } \\
\text { study }\end{array}$ & $\begin{array}{l}\text { Previous } \\
\text { study }\end{array}$ & $P$ \\
\hline Emphysematous changes & $\begin{array}{c}2 \\
(2-3)\end{array}$ & $\begin{array}{c}2 \\
(2-3)\end{array}$ & 1.00 \\
\hline Interstitial congestion & $\begin{array}{c}2 \\
(1-2)\end{array}$ & $\begin{array}{c}2 \\
(1-2)\end{array}$ & 0.23 \\
\hline Alveolar haemorrhage & $\begin{array}{c}1 \\
(1-1)\end{array}$ & $\begin{array}{c}1 \\
(0-1)\end{array}$ & 0.60 \\
\hline Alveolar neutrophil infiltration & $\begin{array}{c}2 \\
(2-2)\end{array}$ & $\begin{array}{c}2 \\
(1-3)\end{array}$ & 1.00 \\
\hline Alveolar macrophage proliferation & $\begin{array}{c}3 \\
(2-3)\end{array}$ & $\begin{array}{c}2 \\
(1-2)\end{array}$ & 0.23 \\
\hline $\begin{array}{l}\text { Alveolar type II pneumocytes } \\
\text { proliferation }\end{array}$ & $\begin{array}{c}2 \\
(2-2)\end{array}$ & $\begin{array}{c}2 \\
(2-2)\end{array}$ & 0.95 \\
\hline Interstitial lymphocytes proliferation & $\begin{array}{c}2 \\
(1-2)\end{array}$ & $\begin{array}{c}2 \\
(1-2)\end{array}$ & 0.82 \\
\hline Interstitial thickening & $\begin{array}{c}2 \\
(1-2)\end{array}$ & $\begin{array}{c}2 \\
(2-3)\end{array}$ & 0.05 \\
\hline Hyaline membranes formation & $\begin{array}{c}0 \\
(0-0) \\
\end{array}$ & $\begin{array}{c}0 \\
(0-1)\end{array}$ & 0.17 \\
\hline Interstitial fibrosis & $\begin{array}{c}1 \\
(1-1) \\
\end{array}$ & $\begin{array}{c}2 \\
(1-3)\end{array}$ & 0.02 \\
\hline Organization of alveolar exudate & $\begin{array}{c}1 \\
(1-2)\end{array}$ & $\begin{array}{c}1 \\
(0-1)\end{array}$ & 0.19 \\
\hline Total score & $\begin{array}{c}18 \\
(14-18)\end{array}$ & $\begin{array}{c}18 \\
(16-19)\end{array}$ & 0.43 \\
\hline
\end{tabular}

Results of animals ventilated with high PEEP and low $V_{T}$ for $36 \mathrm{~h}$ and with no PEEP and low $V_{T}$ for $18 \mathrm{~h}(n=5)$ (present study) were compared with those of animals ventilated with no PEEP and low $\mathrm{V}_{\mathrm{T}}$ for $54 \mathrm{~h}(n=12)$ (previous study) [3]. Alterations were graded from 0 to 4 , with higher scores indicating more severe and diffuse abnormalities. Total score was the sum of all individual scores. $P$ values refer to Mann-Whitney rank sum test. PEEP, positive end-expiratory pressure; $\mathrm{V}_{\mathrm{T}}$, tidal volume.

largely positive water balance (increased pulmonary blood volume) and non-specific alterations in lung histology. Of note, in our setting, pulmonary oedema is always a clearcut diagnosis: lung weight increases by 300 to $600 \mathrm{~g}$, respiratory system and lung compliance largely and progressively decrease, and hypoxemia and hypercapnia are always severe $[3,4]$. None of these changes occurred in this present series of animals.

Reasons why high PEEP and low $\mathrm{V}_{\mathrm{T}}$ do not cause pulmonary oedema, despite resulting in extremely large lung inflation, are not known. On one side, avoidance of large $\mathrm{V}_{\mathrm{T}}$ (and high inspiratory flows) may have a major role as lungs behave as viscoelastic bodies that will fail if elongated too much (and too rapidly) [4,29]. On the other side, high PEEP may have a direct protective effect, diminishing inherent pulmonary heterogeneity and local stress amplification [30].

Our present and past [4] results support maximal lung recruitment and minimal tidal ventilation, as during lowfrequency positive-pressure ventilation with extracorporeal carbon dioxide removal [31]. However, caution is advised in translating data from pre-clinical experience to humans with injured lungs. For instance, another strategy based on the same sound rationale - high-frequency oscillatory ventilation - recently failed to benefit patients with acute respiratory distress syndrome [32,33], despite promising pre-clinical results.

Some limitations of this study deserve a comment. First, only five animals were enrolled because, even in such a small group, results were highly consistent and reproducible. Second, haemodynamic monitoring did not include echocardiography. Although some degree of tricuspid regurgitation may have occurred during the first part of the study (undermining cardiac output measurement), this likely reversed once PEEP had been removed. By that time, not only cardiac output but several other haemodynamic variables (for instance, blood pressure, diuresis, urinary electrolytes, arteriovenous oxygen difference and lactatemia) were normal (or even above normal). The bulk of the data strongly suggest that low cardiac output was not an issue, at least during the second part of the study. Third, integrity and permeability of the blood-gas barrier were not directly assessed and minor changes cannot be completely excluded; but still, pulmonary oedema, de facto, never occurred. Finally, lung injury may have rapidly reversed once overinflation had been suddenly removed [22]; however, lowering mean airway pressure once the blood-gas barrier has been damaged usually causes alveolar flooding, with precipitous deterioration of lung mechanics and gas exchange [27].

\section{Conclusions}

Ventilation with high PEEP and low $\mathrm{V}_{\mathrm{T}}$ does not cause oedema in healthy lungs, not even after PEEP has been suddenly removed and pulmonary haemodynamics have returned to normal. This suggests that large, but mainly static, lung inflation does not permanently alter the integrity and permeability of the blood-gas barrier.

\section{Key messages}

- Healthy lungs ventilated with high PEEP and low $V_{T}$ do not develop pulmonary oedema, even if globally inflated up to their total capacity.

- High PEEP (and low $\mathrm{V}_{\mathrm{T}}$ ) do not merely hydrostatically counteract pulmonary fluid extravasation.

- Mechanical ventilation with high PEEP and low $\mathrm{V}_{\mathrm{T}}$ does not grossly injure the blood-gas barrier in healthy lungs.

\section{Additional material}

Additional file 1: Bland-Altman plot of lung weight measured with balance vs. CT scan. Five other healthy piglets $(18 \pm 1 \mathrm{~kg})$ underwent lung $\mathrm{CT}$ at $\mathrm{O} \mathrm{cmH}_{2} \mathrm{O}$ of airway pressure and were then sacrificed and exsanguinated. Results of quantitative analysis of CT scan were compared with excised lung weight, measured on a balance. The Bland-Altman plot of lung weight measured with the two techniques show a bias $-91 \mathrm{~g}$, 
limits of agreement $-128--54 \mathrm{~g}$ ). Of note, in piglets of similar weight, pulmonary blood volume should be around $90 \mathrm{ml}$ (see [28]) $\mathrm{CT}$, computed tomography.

Additional file 2: Additional methods. Further details on surgical preparation, quantitative analysis of lung $\mathrm{CT}$, haemodynamic protocol, sacrifice and autopsy are shown. CT, computed tomography.

Additional file 3: Baseline lung CT. Results of quantitative analysis of lung $\mathrm{CT}$ scans, which allows for exact computation of lung volumes and capacities and volume of gas due to PEEP. CT, computed tomography; PEEP, positive end-expiratory pressure.

Additional file 4: Additional haemodynamic variables throughout the experiment. Urinary output (panel $\mathbf{A}, n=5$ ), water balance (panel B, $n=5$ ), urinary electrolytes (panel $\mathbf{C}$ and $\mathbf{D}, n=4$ ), arteriovenous oxygen difference (panel $\mathbf{E}, n=5$ ), blood lactate (panel $\mathbf{F}, n=5$ ), and rate of norepinephrine infusion (panel $\mathbf{G}, n=5$ ) were recorded at baseline (B), during ventilation with high PEEP and low $V_{T}(36 h)$ and during ventilation with no PEEP (ZEEP) and low $V_{T}(18 \mathrm{~h}) . P$ values refer to one-way RM ANOVA (on ranks if appropriate); ${ }^{*} P<0.05$ vs. B (HolmSidak or Dunn's method). B, baseline; PEEP, positive end-expiratory pressure; RM ANOVA, repeated measures analysis of variance; $V_{T}$, tidal volume; ZEEP, zero end-expiratory pressure.

Additional file 5: Lung function during ventilation with high PEEP and low $\mathbf{V}_{\mathbf{T}}$. Respiratory system mechanics (panel $\mathbf{A}$ ) lung mechanics (panel B), and gas exchange (panel C and D) were recorded during 36 $h$ of ventilation with high PEEP and low $V_{\text {T. }}$. Oesophageal pressure at 0 $\mathrm{CmH}_{2} \mathrm{O}$ of airway pressure was assumed to have changed linearly from the value recorded at baseline (B) $\left(\right.$ at $\left.0 \mathrm{cmH}_{2} \mathrm{O}\right)$ to the value recorded at time 0 of the ZEEP phase. $P$ values refer to one-way RM ANOVA (on ranks if appropriate); ${ }^{*} P<0.05$ vs. B (Holm-Sidak or Dunn's method). B, baseline; PEEP, positive end-expiratory pressure; RM ANOVA, repeated measures analysis of variance; $V_{T}$, tidal volume; ZEEP, zero end-expiratory pressure.

Additional file 6: Autoptic lung appearance. Lungs of animals ventilated with high PEEP and low $V_{T}$ for $36 \mathrm{~h}$ and with no PEEP and low $V_{T}$ for $18 \mathrm{~h}$ (present study) are shown in panel $\mathbf{A}$. For comparison, lungs of animals ventilated for $54 \mathrm{~h}$ with no PEEP and low $\mathrm{V}_{\mathrm{T}}$ (lung weight changed from 377 to $220 \mathrm{~g}$ ) (panel B), with no PEEP and large $V_{T}$ (close to inspiratory capacity) (lung weight increased from 395 to 721 g) (panel C) and with high PEEP and low $V_{T}$ for $54 \mathrm{~h}$ (lung weight changed from 282 to $290 \mathrm{~g}$ ) (panel D) are shown. PEEP, positive endexpiratory pressure; $V_{T}$, tidal volume.

\section{Abbreviations}

CT: computed tomography; FRC: functional residual capacity; IC: inspiratory capacity; PEEP: positive end-expiratory pressure; RM ANOVA: repeated measures analysis of variance; TLC: total lung capacity; $\mathrm{V}_{\mathrm{T}}$ : tidal volume; ZEEP: zero end-expiratory pressure.

\section{Competing interests}

This study was funded in part by GE Healthcare. The authors declare that they have no competing interests that can have influenced the submitted manuscript.

\section{Authors' contributions}

AP participated in the study design, statistical analysis and wrote the manuscript. DTA participated in the study design, ran the experiments, performed statistical analysis and revised the manuscript. GEl participated in the study design, ran the experiments, performed statistical analysis and revised the manuscript. MM participated in the study design and data acquisition. BC participated in data acquisition and analysis.MM participated in data acquisition and analysis. LZ participated in data acquisition and analysis. SG performed the surgical preparation and revised the manuscript. LL performed the lung computed tomography and participated in the study design. LG participated in the study design and revised the manuscript. All authors read and approved the final version of the manuscript.

\section{Acknowledgements}

This study was supported in part by an Italian grant provided by Fondazione Fiera di Milano for Translational and Competitive Research (2007, Luciano Gattinoni).

We are grateful to Fabio Ambrosetti for his valuable technical support.

\section{Authors' details}

'Dipartimento di Anestesia, Rianimazione (Intensiva e Subintensiva) e Terapia del Dolore, Fondazione IRCCS Ca' Granda - Ospedale Maggiore Policlinico, via Francesco Sforza, 35, 20122 Milan, Italy. ${ }^{2}$ Dipartimento di Fisiopatologia Medico-Chirurgica e dei Trapianti, Università degli Studi di Milano, Via Francesco Sforza, 35, 20122 Milan, Italy. ${ }^{3}$ Centro di Ricerche Chirurgiche Precliniche, Fondazione IRCCS Ca' Granda - Ospedale Maggiore Policlinico, Università degli Studi di Milano, Via Francesco Sforza, 35, 20122 Milan Italy. ${ }^{4}$ Dipartimento di Radiologia, Fondazione IRCCS Ca' Granda - Ospedale Maggiore Policlinico, via Francesco Sforza, 35, 20122 Milan, Italy.

Received: 8 January 2013 Revised: 31 May 2013 Accepted: 11 July 2013 Published: 11 July 2013

\section{References}

1. The Acute Respiratory Distress Syndrome Network: Ventilation with lower tidal volumes as compared with traditional tidal volumes for acute lung injury and the acute respiratory distress syndrome. N Engl J Med 2000, 342:1301-1308.

2. Gattinoni L, Protti A, Caironi P, Carlesso E: Ventilator-induced lung injury: the anatomical and physiological framework. Crit Care Med 2010, 38: S539-S548.

3. Protti A, Cressoni M, Santini A, Langer T, Mietto C, Febres D, Chierichetti M, Coppola S, Conte G, Gatti S, Leopardi O, Masson S, Lombardi L, Lazzerini M, Rampoldi E, Cadringher P, Gattinoni L: Lung stress and strain during mechanical ventilation: any safe threshold? Am J Respir Crit Care Med 2011, 183:1354-1362.

4. Protti A, Andreis DT, Monti M, Santini A, Sparacino CC, Langer T, Votta E, Gatti S, Lombardi L, Leopardi O, Masson S, Cressoni M, Gattinoni L: Lung stress and strain during mechanical ventilation: any difference between statics and dynamics? Crit Care Med 2013, 41:1046-55.

5. Staub NC: Pulmonary edema due to increased microvascular permeability to fluid and protein. Circ Res 1978, 43:143-151.

6. Webb HH, Tierney DF: Experimental pulmonary edema due to intermittent positive pressure ventilation with high inflation pressures. Protection by positive end-expiratory pressure. Am Rev Respir Dis 1974, 110:556-565.

7. Dreyfuss D, Basset G, Soler P, Saumon G: Intermittent positive-pressure hyperventilation with high inflation pressures produces pulmonary microvascular injury in rats. Am Rev Respir Dis 1985, 132:880-884.

8. Dreyfuss D, Saumon G: Role of tidal volume, FRC, and end-inspiratory volume in the development of pulmonary edema following mechanical ventilation. Am Rev Respir Dis 1993, 148:1194-1203.

9. Cournand A, Motley HL, Werko L, Richards DW: Physiological studies of the effects of intermittent positive pressure breathing on cardiac output in man. Am J Physiol 1948, 152:162-174.

10. Zabner J, Angeli LS, Martinez RR, Sánchez de León R: The effects of graded administration of positive end expiratory pressure on the fluid filtration rate in isolated rabbit lungs, using normal lungs, hydrostatic oedema lungs and oleic acid induced oedema. Intensive Care Med 1990, 16:89-94.

11. Institute of Laboratory Animal Resources, Commission on Life Sciences, National Research Council: Guide for the care and use of laboratory animals Washington: National Academy Press; 1996.

12. Gattinoni L, Caironi P, Pelosi P, Goodman LR: What has computed tomography taught us about the acute respiratory distress syndrome? Am J Respir Crit Care Med 2001, 164:1701-1711.

13. Panigada M, Berra L, Greco G, Stylianou M, Kolobow T: Bacterial colonization of the respiratory tract following tracheal intubation-effect of gravity: an experimental study. Crit Care Med 2003, 31:729-737.

14. Craven KD, Wood LD: Extrapericardial and esophageal pressures with positive end-expiratory pressure in dogs. J Appl Physiol 1981, 51:798-805.

15. Tsuno K, Miura K, Takeya M, Kolobow T, Morioka T: Histopathologic pulmonary changes from mechanical ventilation at high peak airway pressures. Am Rev Respir Dis 1991, 143:1115-1120. 
16. Bo G, Hauge A, Nicolaysen G: Alveolar pressure and lung volume as determinants of net transvascular fluid filtration. J Appl Physio/ 1977, 42:476-482.

17. Goldberg HS, Mitzner W, Batra G: Effect of transpulmonary and vascular pressures on rate of pulmonary edema formation. J Appl Physiol 1977, 43:14-19.

18. Huchon GJ, Hopewell PC, Murray JF: Interactions between permeability an hydrostatic pressure in perfused dogs' lungs. J Appl Physiol 1981, 50:905-911.

19. Egan EA: Lung inflation, lung solute permeability, and alveolar edema. J Appl Physiol 1982, 53:121-125.

20. Russell JA, Hoeffel J, Murray JF: Effect of different levels of positive endexpiratory pressure on lung water content. J Appl Physiol 1982, 53:9-15.

21. Barach AL, Martin J, Eckman M: Positive pressure respiration and its application to the treatment of acute pulmonary edema. Ann Int Med 1938, 12:754-795.

22. Prewitt RM, McCarthy J, Wood LD: Treatment of acute low pressure pulmonary edema in dogs: relative effects of hydrostatic and oncotic pressure, nitroprusside, and positive end-expiratory pressure. J Clin Invest 1981, 67:409-418.

23. Young JS, Rayhrer CS, Edmisten TD, Cephas GA, Tribble CG, Kron IL: Sodium nitroprusside mitigates oleic acid-induced acute lung injury. Ann Thorac Surg 2000, 69:224-227.

24. Staub NC: Pulmonary edema: physiologic approaches to management. Chest 1978, 74:559-564.

25. Sibbald WJ, Short AK, Warshawski FJ, Cunningham DG, Cheung H: Thermal dye measurements of extravascular lung water in critically ill patients. Intravascular Starling forces and extravascular lung water in the adult respiratory distress syndrome. Chest 1985, 87:585-592.

26. National Heart, and Blood Institute Acute Respiratory Distress Syndrome (ARDS) Clinical Trials Network, Wioedemann HP, Wheeler AP, Bernard GR, Thompson BT, Hayden D, deBoisblanc B, Connors AF Jr, Hite RD, Harabin AL: Comparison of two fluid-management strategies in acute lung injury. N Engl J Med 2006, 354:2564-2575.

27. Kubiak BD, Albert SP, Gatto LA, Trikha G, El-Zammar O, Nieman GF: Loss of airway pressure during HFOV results in an extended loss of oxygenation: a retrospective animal study. J Surg Res 2010, 162:250-257.

28. Ugander M, Kanski M, Engblom H, Götberg M, Olivecrona GK, Erlinge D, Heiberg E, Arheden H: Pulmonary blood volume variation decreases after myocardial infarction in pigs: a quantitative and noninvasive MR imaging measure of heart failure. Radiology 2010, 256:415-423.

29. Tschumperlin DJ, Oswari J, Margulies AS: Deformation-induced injury of alveolar epithelial cells. Effect of frequency, duration, and amplitude. Am J Respir Crit Care Med 2000, 162:357-362.

30. Mead J, Takishima T, Leith D: Stress distribution in lungs: a model of pulmonary elasticity. J Appl Physiol 1970, 28:596-608.

31. Gattinoni L, Pesenti A, Kolobow T, Damia G: A new look at therapy of the adult respiratory distress syndrome: motionless lungs. Int Anesthesiol Clin 1983, 21:97-117.

32. Ferguson ND, Cook DJ, Guyatt GH, Mehta S, Hand L, Austin P, Zhou Q, Matte A, Walter SD, Lamontagne F, Granton JT, Arabi YM, Arroliga AC, Stewart TE, Slutsky AS, Meade MO, OSCILLATE Trial Investigators, Canadian Critical Care Trials Group: High-frequency oscillation in early acute repiratory distress syndrome. N Engl J Med 2013, 368:795-805.

33. Young D, Lamb SE, Shah S, MacKenzie I, Tunnicliffe W, Lall R, Rowan $K$, Cuthbertson BH, OSCAR Study Group: High-frequency oscillation for acute repiratory distress syndrome. N Engl J Med 2013, 368:806-813.

doi:10.1186/cc12810

Cite this article as: Protti et al:: High positive end-expiratory pressure: only a dam against oedema formation? Critical Care 2013 17:R131.

\section{Submit your next manuscript to BioMed Central and take full advantage of:}

- Convenient online submission

- Thorough peer review

- No space constraints or color figure charges

- Immediate publication on acceptance

- Inclusion in PubMed, CAS, Scopus and Google Scholar

- Research which is freely available for redistribution 